\title{
SPIKE PROTECTION DEVICE FOR ELECTRONICS AND COMMUNICATION APPLIANCES
}

\author{
H. A. ADAMU AND I. YUSUF
}

(Received 19, June 2007; Revision Accepted 13, February 2008)

\begin{abstract}
ABSTARACT
Experience shows that most failures of electronic and communication equipment result from damage caused by external electrical disturbances in the form of overvoltage, undervoltage, surge, sag, spike, or voltage dropout (blackout), the status of which is determined by the amplitude and duration of the disturbance. Spikes, the most damaging of all, appear at random intervals on power supply cables that lead to equipment damage. Different types of voltage sensitive components have been developed for the purpose of spike suppression. This work provides an effective spike suppression device (SSD), meant for single equipment protection, realized by utilizing the fast response characteristics of a Varistor, and combined with the high current sinking capabilities of a Gas discharge tube.
\end{abstract}

KEY WORDS: Spikes, suppressor, varistor, gas arrestor

\subsection{INTRODUCTION}

The operations of electronic systems can severally be affected by lightning activity or electrical switching events, both of which can cause very short duration increase in voltage, or mains power with devastating consequences. All sort of electronic equipment are at risk: computers, building management systems, PABX telephone exchanges, CCTV equipment, fire and burglar alarms, UPS, programmable logic controllers, plant sensors, telemetry and data acquisition equipment, and so on.

The most damaging of all electrical disturbances that lead to the destruction of electronic and communication equipment is a short duration voltage impulses known as spikes (IAEA, 1994). Because of their extreme amplitudes, spike can cause fatal damage to vital components of equipment. Although spikes have very short duration, lasting for less than a thousandth of a second, their intensity (amplitude) may reach a peak of several thousands of volts. Therefore, spike suppression forms the first step towards an effective programme for protection of electronic/communication equipment.

Voltage spikes do not travel easily through mains wiring. They exhibit similar electrical characteristics with high frequency radio wave, and get attenuated much as the radio signal would be if transmitted through ordinary conductor. This forms the basis of spike suppressor device (SSD). An SSD appears to a spike as a short circuit when connected across the mains, with the energy of the spike dissipated on the SSD and in the electrical resistance of the cabling.

Switching events in the power supply network as well as lightening strikes are the main causes for spikes. This design is limited to protection of spike resulting from switching events caused by normal load switching from electric utility company, individual load switching, or accidental events such as short-circuits, leakage, or faulty equipment. Whenever a large current is switched on or off, the effects of induction generate a short-lived high voltage that may launch a spike into the supply network. This travels along the supply cables at near the speed of light, dissipating energy as it goes. Even after a kilometre, its amplitude is high enough to cause fatal damage to delicate equipment.

\subsection{Objectives of the Paper}

The paper offers an effective and cheap means of protecting electronic and communication equipment from spikes resulting from switching event, limited to single equipment protection.

\subsection{THEORY OF TRANSIENT OVERVOLTAGE}

A transient overvoltage (also called 'spikes' or 'surges' or 'glitches') is a short duration (in the range of microseconds to few milliseconds) increase in voltage (up to thousands of volts) measured between two or more conductors. Figure 2.1 shows the appearance of transient overvoltage superimposed on a normal mains power supply line.

H. A. Adamu, Centre for Energy Research and Training, Ahmadu Bello University, P. M. B1014 Zaria

I. Yusuf, Centre for Energy Research and Training, Ahmadu Bello University, P. M. B1014 Zaria 


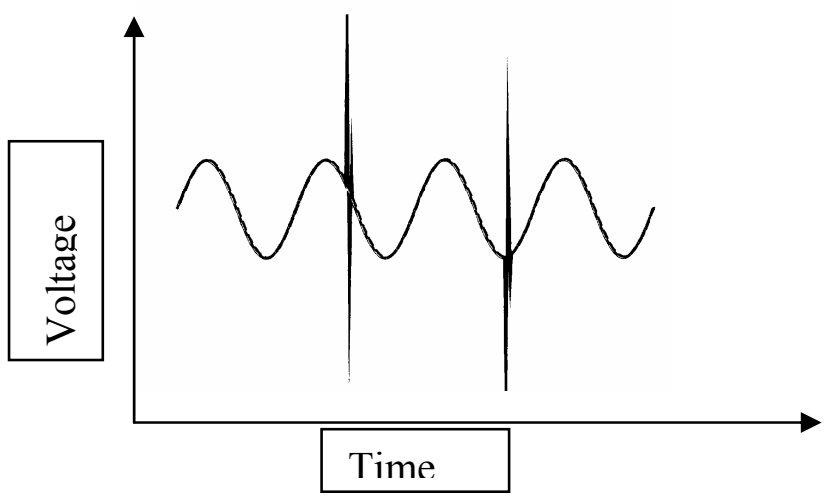

Figure 2.1: Transient overvoltage

\subsection{Causes of Transient Overvoltage}

Transient overvoltage has two main causes: Lightning and Electrical Switching events

\section{- $\quad$ Lightning}

Lightning discharge may generate currents up to 530,000 amperes, though $200,000 \mathrm{~A}$ is an accepted upper limit (Furze \& Co. Ltd., 1996). Lightning can cause transient overvoltage through direct strikes to incoming electrical services, and indirect strikes, coupled into electrical services through resistive and capacitive effects.

\section{- $\quad$ Electrical Switching Events}

Transient overvoltage caused by electrical switching events is very common and can be source of considerable interference. Current flowing through a conductor creates a magnetic field in which energy is stored. When the current is interrupted or switched off, the energy stored in the magnetic field is suddenly released. In an attempt to dissipate itself, it becomes a high voltage transient. Higher currents and longer lengths of conductor, both contribute to more energy stored and also released. This is why inductive loads such as motors, transformers and electrical drives are all common causes of transient overvoltage.

\subsection{Effects of Transient Overvoltage}

Transient overvoltage, whether caused by lightning or electrical switching, have similar effects as shown in figure 2.2. The effects are as follows:

\section{- Disruption}

In this case, no physical damage is caused, but the logic and analogue levels of the system are upset; causing data loss, data and software corruption, unexplained computer crashes, spurious tripping of residual current devices, and so on. The system can be reset often by switching off and on.

\section{- Degradation}

Long term exposure to low level transient overvoltage will degrade electronic components and circuitry, reducing equipment lifetime and increasing the likelihood of failure.

\section{- Damage}

Large transient overvoltages can cause damage to components, circuit boards and I/O cards.

\section{- Downtime}

Unnecessary disruption, component degradation and damage all result in equipment and system downtime, resulting in decrease in productivity.

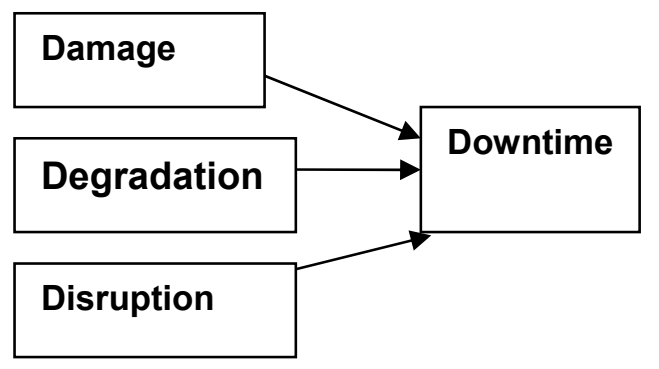

Figure 2.2: Effects of transient overvoltage

\subsection{WORKING PRINCIPLES OF SSDs}

A range of voltage sensitive components has been developed for the purpose of spike suppression. Such components include gas discharge tubes (gas arrestor), varistors diodes, and transorbs, each with distinctive characteristics (IAEA TECDOC, 1999; www.bluestone.co.th, 2002). Some absorb a lot of energy, but respond slowly, while others respond fast but cannot handle large spikes. The components can be used singly or in combination, to produce SSDs with different capacities and specifications. This design utilizes the fast response characteristics of a varistor and the high current sinking capability of a gas arrester. 


\subsection{Working Principles of a Varistor}

Varistors are non-linear voltage dependent resistors (VDR) with a symmetrical voltage/current characteristic as shown in fig. 3.1 (a). Figure 3.1 (b) shows the symbol of Varistor.

When an impulse voltage is applied across a varistor, its resistance value decreases with increasing voltage and clips the voltage across it at its rated value, and converts the excessive energy to heat. They react fast with operating times in low nanosecond range. They are used in the medium protection stage with discharge currents of $2.5 \mathrm{kA}$ to $5 \mathrm{kA}$. An unpleasant fact is that varistors may drop their operating voltage in case of overloads due to internal micro short circuits. The effect is a self destroying avalanche. A fuse protection is recommended (Milton Kaufman et al., 1988).

\subsection{Working Principles of a Gas Arrestor}

Gas arrester is mainly used to switch high voltage pulse to ground. Its powerful switch function enables it to solve the coarse protection of power lines. When an impulse voltage is applied across the electrodes of a Gas arrester, the variation of its impedance is switched from Gig ohms into milliohms in a turn-on action of a gas discharge. This action is initiated by ionization and ignition due to a pass over of a certain voltage level, causing a glow discharge. As the voltage further increases, the sustained discharge mode changes into arc discharge mode. After this, the voltage across the gas arrester becomes constant, even if voltage increases (W. Schmidt et al., 1989, P298). Figure 3.2 shows the symbol of Gas arrestor.

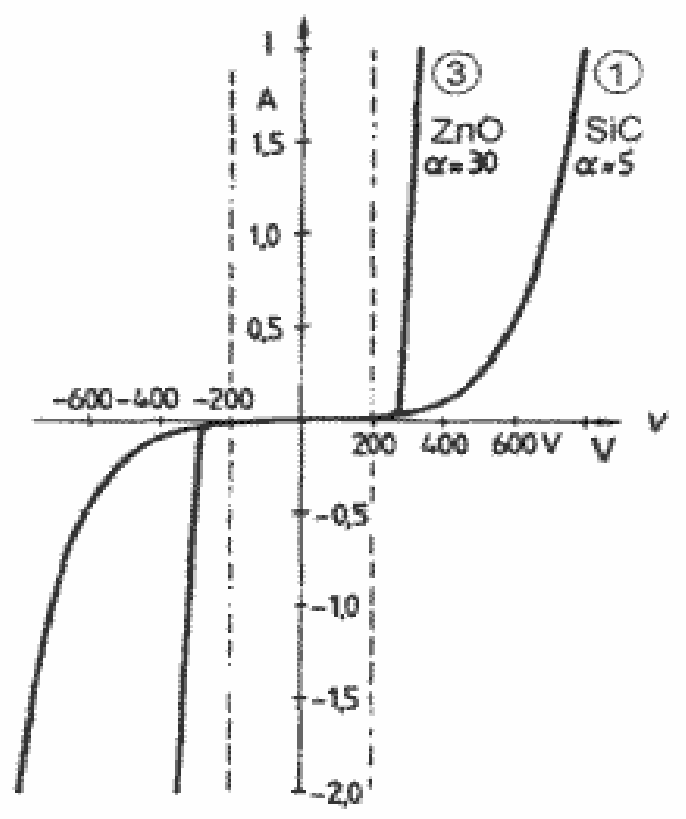

(a)

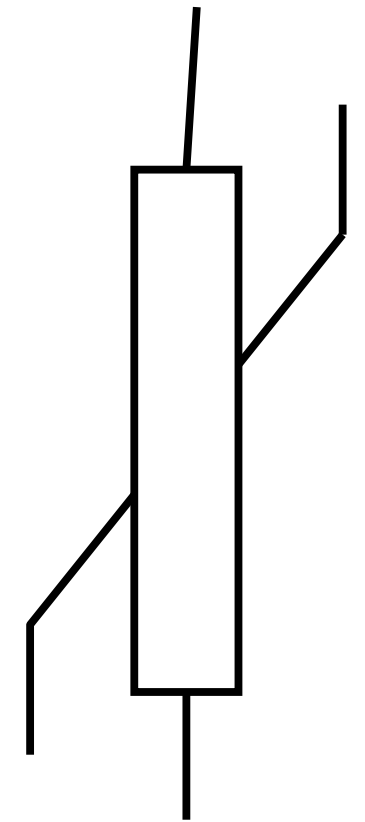

(b)

Figure 3.1: Varistor (a) V-I Characteristic (b) Symbol

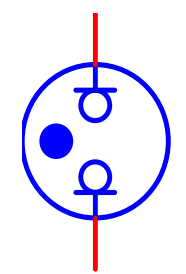

Figure 3.2: Gas arrestor symbol

The most commonly used Gas arresters can discharge transient current up to 10kA. One disadvantage of this device is time dependent ignition behaviour (slow response). It is therefore necessary to connect a safety fuse upstream that interrupts the circuit in the event of line follow currents.

\subsection{CIRCUIT FOR THE SPIKE SUPPRESSION DEVICE (SSD)}

Every reliable SSD must be able to clamp transients and take repetitive hits. However, most SSDs available in Nigerian Markets are susceptible to being damaged in the cause of protecting electronic and communication equipment from spikes. Examples may 
be sighted in air-conditioner supply protection devices, communication equipment supply protection, back - up power supply for IT equipment, to mention but a few.

\subsection{Circuit Description} following:

This SSD circuit is intended to achieve the

- Clamp all Transients

- Take repetitive hits

- Operate in parallel with the load

Therefore, the circuit is independent of equipment current rating. It utilizes two varistors with single gas arrestor, in conjunction with two thermoswitches and a protection status indicator (comprising a resistor bridge and a neon indicator). The Circuit diagram of the SSD is illustrated in figure 4.1.

\subsubsection{Selection of Component}

The components selection for the SSD circuit of Fig. 4.1 is dictated by the author's targeted transient peak of $300 \mathrm{~V}$ at the circuit output, while the component operating parameters are obtained from the components catalogue.

- Varistor

Type: $\quad$ S20k275

Operating Voltage: $275 \mathrm{~V}$

Peak Transient current $4.5 \mathrm{kA}$

Operating Temperature Range: $-40^{\circ} \mathrm{C}$ to $+85^{\circ} \mathrm{C}$

Tolerance: $\quad 10 \%$

- Gas Arrester:

Type: A470X

Sparkover voltage: $470 \mathrm{~V} \quad 20 \%$

Discharge Current: 20kA

- Thermal Switch

Type: $\quad$ S90

Operating Temperature: $90^{\circ} \mathrm{C} \quad 3^{\circ} \mathrm{C}$

- Neon Indicator:

Type: Red

Operating Voltage: 200V - 250V

- Resistor Bridge:

$\mathrm{R}_{1}=\mathrm{R}_{2}=\mathrm{R}_{3}=\mathrm{R}_{4}=85 \mathrm{k} \Omega$

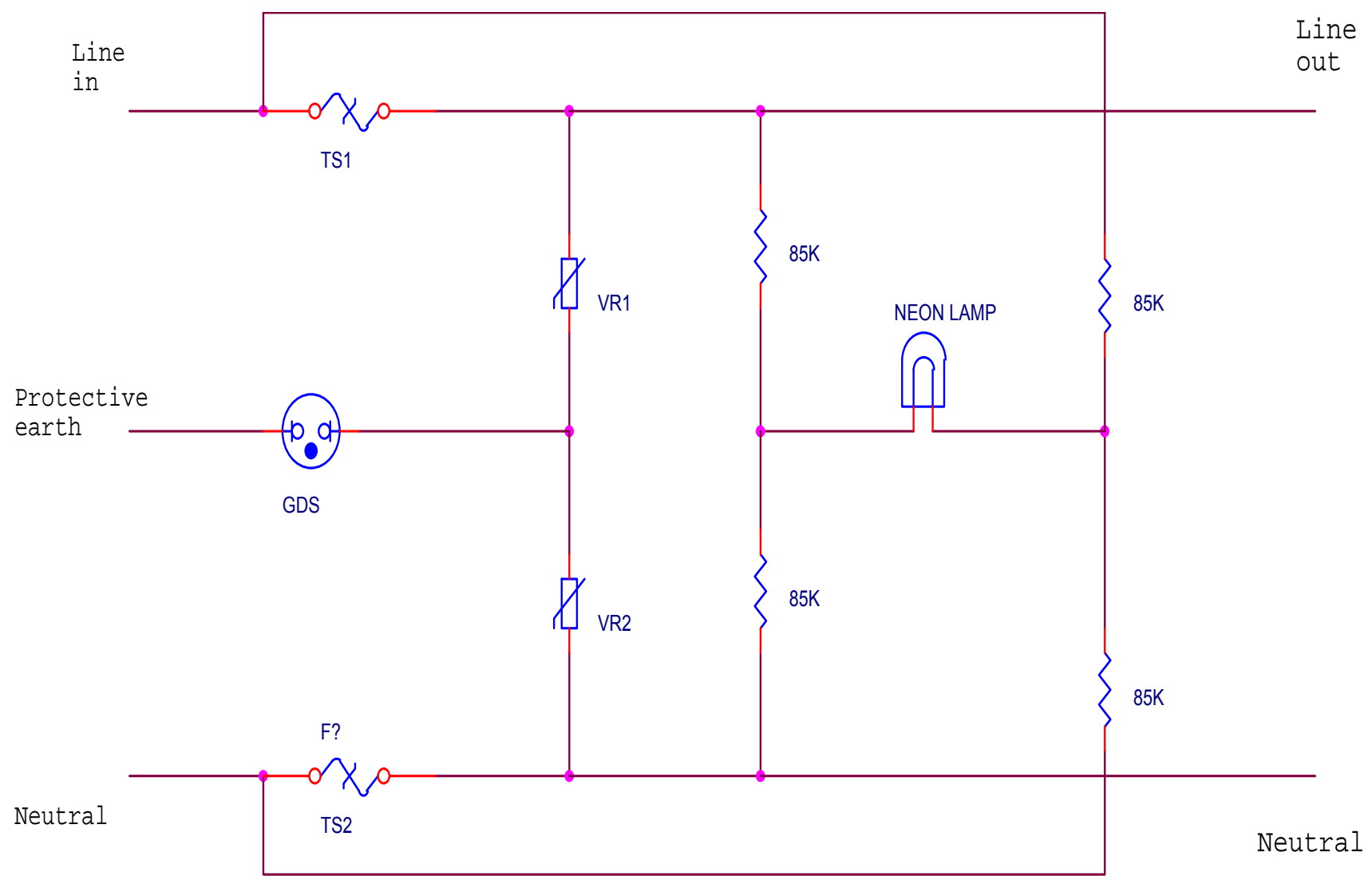

Figure 4.1: SSD circuit diagram

\subsubsection{Circuit Operation}

The aim of combining the two spike suppression devices is to exploit the advantages offered by the individual components and eliminate their short falls. The spike, which appears between line and neutral (differential mode), is limited by the serial connection of the two varistors VR1 and VR2 to about 550V. The spikes that appear between lines or neutral to earth (common mode), are limited by gas arrestor GDS and VR1 or VR2. When the voltage of the spike is above $470 \mathrm{~V}$, the GDS is ignited, representing very low impedance. Thereafter, the serial VR1 and VR2 limit the voltage to $380 \mathrm{~V}$ maximum.

Thermoswitches TS1 and TS2 are thermically connected to VR1 and VR2 respectively and their contacts are normally closed. If the varistor gets heated to its rated operating temperature (due to excessive leakage current resulting form the overloading spike), the contacts of the respective thermoswitch opens irreversibly, thereby isolating the equipment.

Neon indicator, $\mathrm{H}$, indicates the status of the operating condition. For normal operations of the SSD, the Resistor Bridge is such that the voltage drop across 
the neon indicator is zero, hence the neon light remains off. On the other hand, when TS1 or TS2 contacts are open, $\mathrm{H}$ comes on and remains so until normalcy is restored.

\subsection{Tests Performed}

Figures 4.2, 4.3, and 4.4 show the response of the SSD recorded using Tektronix Digital Storage Oscilloscope with 1:100 differential probe. The oscilloscope vertical axis is set at $2 \mathrm{~V}$ per division. Figure 4.2 shows a $1.2 / 50 \mathrm{~s}$ spike of $1000 \mathrm{~V}(2 \times 5 \times 100)$ amplitude applied at the zero crossing point of a $230 \mathrm{~V}$ ac supply, using a Timota Compact Line Simulator. The waveform is generated without an SSD. When only a gas arrestor was connected across the mains supply, the spike was clamped to about $600 \mathrm{~V}$ as illustrated in figure 4.3. Figure 4.4 shows the combined effect of the SSD (with varistor and gas arrestor together) as in the circuit of figure 4.1, when the same spike was applied. The SSD was able to clamp the spike to about 320V. This voltage can be tolerated by most electronics and communication equipment (Schmidt et al., 1989).

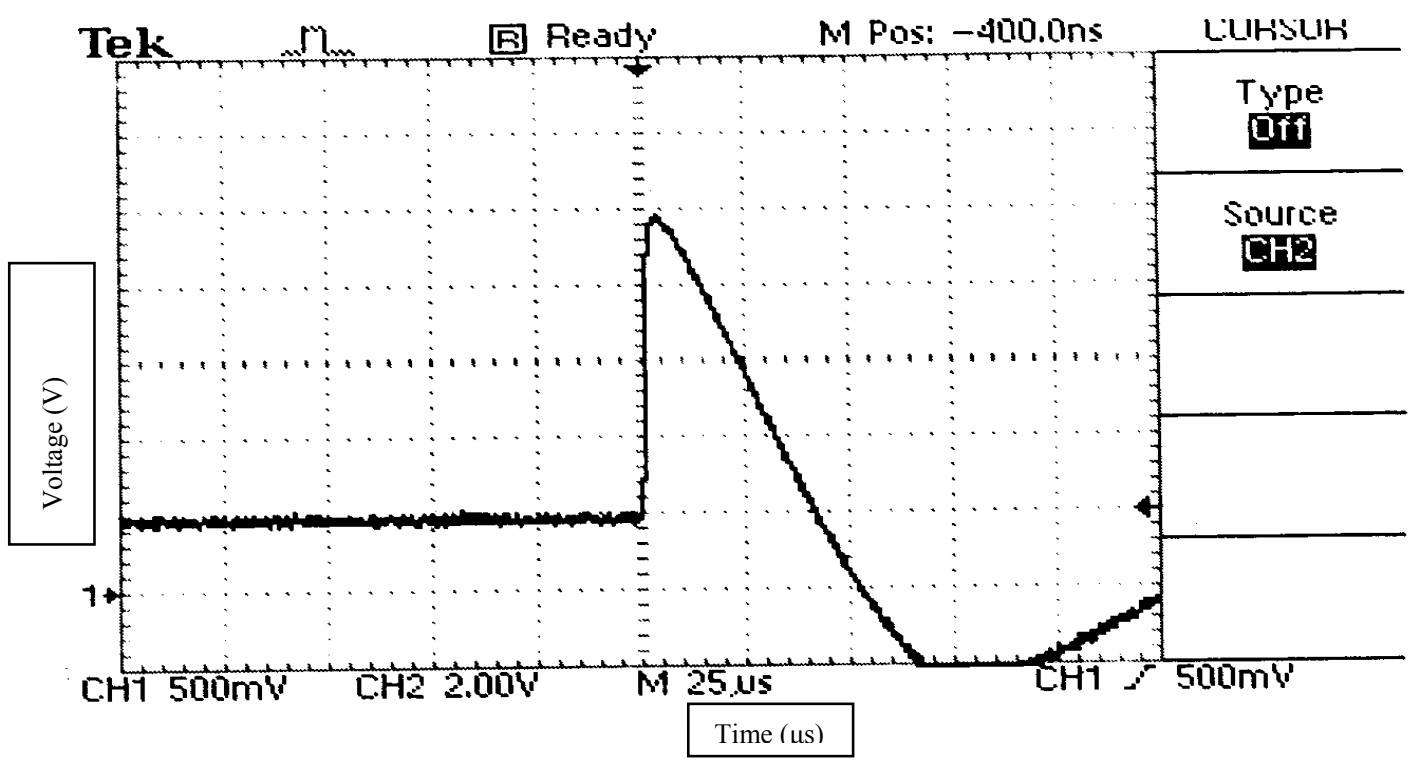

Figure 4.2: SSD output waveform without protection

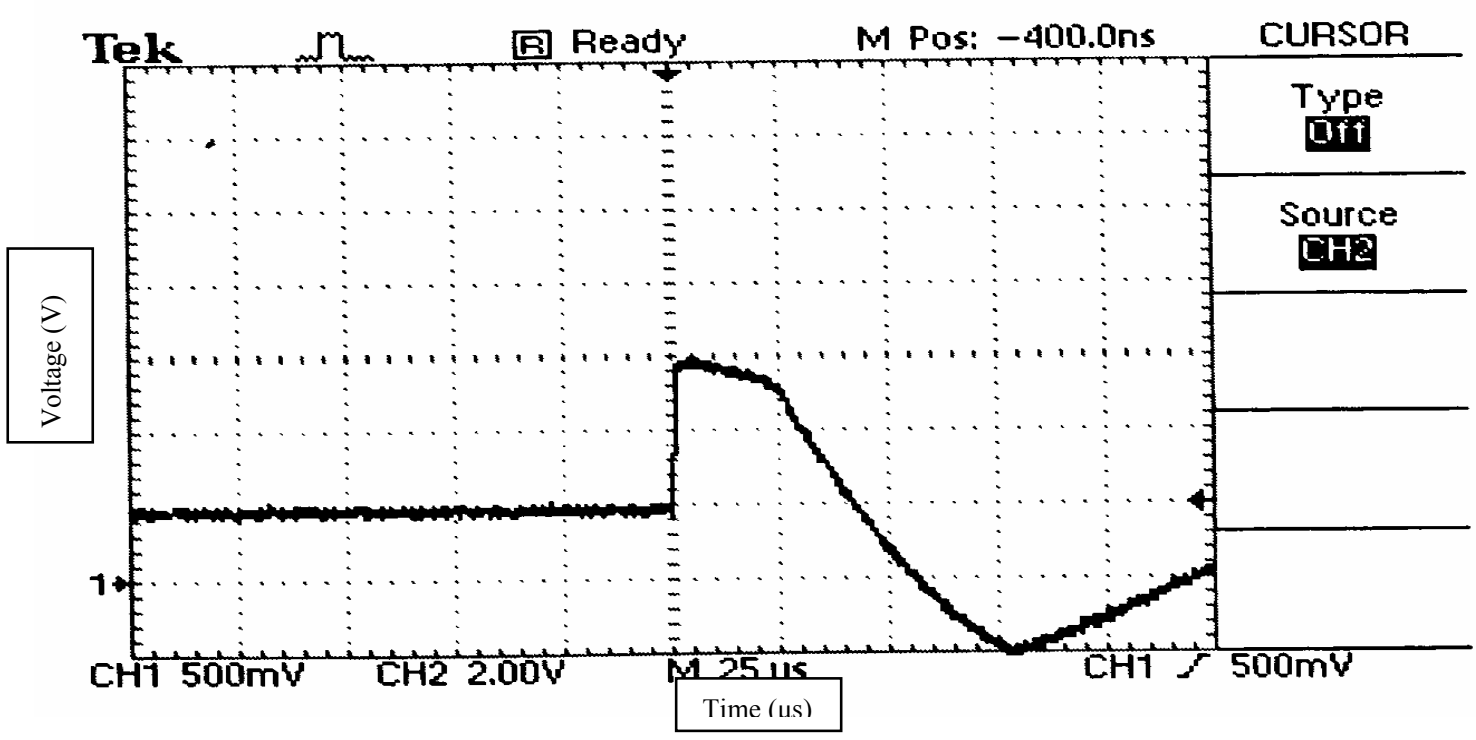

Figure 4.3: SSD output waveform with Gas arrester protection 


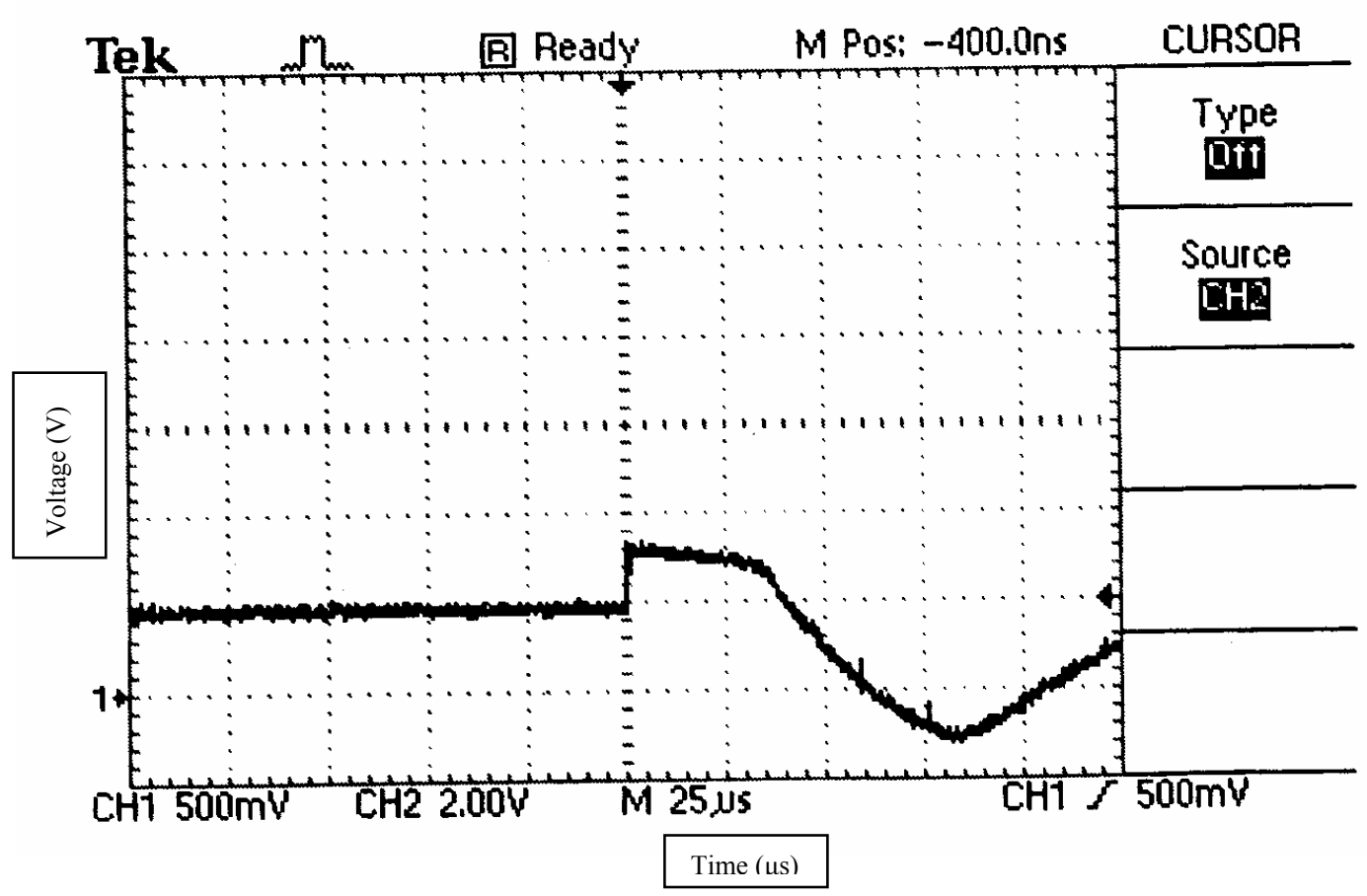

Figure 4.4: SSD output waveform with full protection

\subsection{CONCLUSION}

It is important that the spike protection device fulfils the following requirements:

1. Survivability: The SSD is capable of surviving the worst case transients expected at its intended installation point;

2. Transient control: The device is able to control transients to a level below the susceptibility and vulnerability of the equipment to be protected; and

3. System compatibility: The device does not impair or interfere with the protected system's normal operation.

The circuit of Fig. 4.1 satisfies the set criteria and offers the advantages of simplicity, economy, and reliability. The device would suppress spikes resulting from switching events up to a fault current rating of $4.5 \mathrm{kA}$. The temperature effect due to spikes that usually destroy other commercial SSDs has been adequately taken care of by the introduction of thermo - switches that protect the varistors from overheating. The $320 \mathrm{~V}$ clamping voltage at a maximum duration of $50 \mathrm{~s}$ offered by the SSD can be tolerated by most electronics and communication equipment operated in Nigeria.

\section{REFERENCE}

International Atomic Energy Agency (IAEA), 1994. Handbook on Care, Handling Protection of Nuclear Electronics and Medicine Equipment, Vienna, Austria

International Atomic Energy Agency (IAEA), 1999. Protection of Nuclear Instrument and other Laboratory Equipment, IAEA TECDOC, Vienna, Austria.

Milton Kaufman and Arthur Seidman, 1988. Handbook of Electronics Calculations $2^{\text {nd }}$ Ed, McGrow-Hill,

NY, www.bluestone.co.th/surgeprotection.htm, 2002-1020

www.commmni.com/collmen/glossary.htm, 2005-08-30

W. J. Furse and Co. Ltd. 1996. Electronic system Protection Handbook UK,

W. Schmidt, and K. Feser, 1989. Behaviour of MD surge Arrestor Blocks to Fast Transients, IEEE Trans on Power Delivery, 4, (2): pp298. 